\title{
Distinguishing Predatory from Reputable Publishing Practices
}

\author{
Laura E. Happe, PharmD, MPH
}

\begin{abstract}
SUMMARY
The preponderance of journals with dubious publishing practices has resulted in a new term in academic publishing: predatory journals. Although there is no standard definition, predatory journals generally subvert the traditional peer-reviewed system for financial gain. Common practices of predatory journals include publishing almost all submissions, a lack of transparency about publication fees, aggressive solicitation of contributors irrespective of relevant expertise and credentials, and even closely mimicking names of reputable journals-effectively acting as a decoy to attract authors and readers. Left unchecked, these journals have the potential to threaten the evidence base relied on by managed care pharmacists.

Given the importance of peer-reviewed literature to managed care pharmacy practice, how is one to discern between a predatory journal and a reputable one? There are 5 key practices that distinguish reputable journals. First, reputable journals rely on peer reviewers who are experts in their respective fields to carefully review submitted manuscripts for suitability to publish. Second, reputable journals have a board of experts in relevant areas that serve in an advisory capacity to the editorial staff. Third, reputable journals follow recognized publishing standards to guide their policies, which range from determining authorship, to journal management, to handling allegations of misconduct. Fourth, reputable journals are transparent and fair about their levied fees, avoiding any real or perceived conflict of interest. Finally, reputable journals are indexed in searchable databases that have quality selection criteria for inclusion.

These 5 criteria should be used by managed care authors and researchers when determining where to publish their papers and whether to serve as an editorial board member or peer reviewer when requested. Studies published in journals meeting these criteria can be deemed as reputable and suitable for review by managed care and health policymakers. It is essential that everyone involved in producing and using peer-reviewed literature is informed about the threat of predatory publishing and avoids engaging in any activities with these journals.
\end{abstract}

J Manag Care Spec Pharm. 2020;26(8):956-60

Copyright $\odot 2020$, Academy of Managed Care Pharmacy. All rights reserved.

$\mathrm{P}$ eer-reviewed publishing is a sacred bedrock of the scientific process and scholarship. Without the published literature, we would not have the very evidence required to practice evidence-based medicine and pharmacy. We would lack authoritative references to support treatment recommendations and policy decisions. And, dissemination of scientific innovation would lack the checks and balances pharmacists and policymakers rely on to discern credible work.

Yet peer-reviewed publishing is being threatened by the emergence and growth of predatory journals, according to a joint statement from 3 prominent medical writing societies. ${ }^{1}$ The American Medical Writers Association, the European Medical Writers Association, and the International Society for
Medical Publication Professionals define journals that subvert the peer-review publication system for the sole purpose of financial gain with little evident concern for ethical behavior as predatory.

The term "predatory journals" is attributed to Jeffery Beall, DSc, a librarian at the University of Colorado. ${ }^{2}$ Beginning in 2008, Beall maintained a publicly available website that cataloged predatory publishers and journals, allowing users to check whether a given journal was considered predatory according to his own defined criteria. ${ }^{3}$ The website was taken down mid-2017 under media speculation that he may have been forced to take down the site because of threats or lawsuits. ${ }^{4}$ Nevertheless, the spirit of his work prevails in various venues, including a website with the cached copy of Beall's most recent list (https://beallslist.net/), a Blacklist (questionable journals) and Whitelist (reputable journals) available for a fee from Cabells Scholarly Analytics (http://www2.cabells.com/), and the Think.Check.Submit campaign to help researchers identify trusted journals (https://thinkchecksubmit.org/).

Beall's termed predatory journals practice a range of dubious behaviors. Several closely mimic the name of well-known reputable journals. Listed titles such as the Journal of Advances in Internal Medicine or Annals of Medical and Biomedical Sciences can be easily confused with top-tier journals such as the Annals of Internal Medicine. ${ }^{3}$ Predatory journals are also known for aggressively soliciting authors, editors, and board members, often without relevant expertise or credentials. For example, I was recently invited to submit a paper on "mathematically oriented engineering science and simulation"-a topic far outside of my area of expertise. I suspect many of my peers and colleagues have received similar invitations to join editorial boards or submit papers. Both activities are regarded as professional distinctions and ways for experts to give something back to their respective professions; as such, people may be inclined to accept, not realizing they are engaging with a predatory journal.

With the pressure in academic institutions to "publish or perish," some authors may even knowingly seek out predatory journals to advance their careers. A small study at a Canadian business school found that the majority of faculty had published in predatory journals, and there was a positive correlation between predatory publications and receipt of internal research awards. ${ }^{5}$ Researchers from the Hanken School of Economics in Finland purport that most authors are not tricked into predatory publications, but instead take a calculated risk. ${ }^{6}$ They attribute these unscrupulous actions at least in part to institutions in developing countries that 
are being held to the same publishing standard as developed nations, yet they lack the means to succeed in such a model. At the Journal of Managed Care \& Specialty Pharmacy (JMCP), we have observed a substantial increase in submissions from developing countries in recent years; however, most of these submissions are rejected because they lack relevance to our readers. Our experience at JMCP suggests that there is an increase in publishing efforts from these developing countries but can go no further in supporting the hypothesis made by the Hanken authors.

Managed care professionals produce research and use research to make evidence-based decisions. With the growth of predatory journals, it can be difficult for authors and readers to distinguish these publications from trusted, reputable journals. To help make this distinction, several lists have been published that help users to identify predatory journals., ${ }^{3,7-10}$ These resources can be extremely useful when evaluating a particular journal; however, they provide readers with little detail about the publishing practices of reputable journals. In this article, I explain 5 publishing practices that distinguish credible journals from predatory journals, using JMCP as an illustrative example (Table 1). In this way, I not only highlight good publishing practices, but I share with readers the inner workings of JMCP.

\section{Reputable journals follow a peer-review process.}

Peer review is the primary hallmark of academic publishing and may be greatly compromised or bypassed altogether by predatory journals, which tend to accept nearly all submissions. To be able to discern predatory peer review, it is important to understand how a complete peer-review process functions.

Papers submitted to JMCP go through a rigorous, multistep review process. First, journal staff performs a preliminary review of each article to ensure that the submission is complete and compliant with general article guidelines, such as word count. Next, articles are assigned to an editor who conducts a preliminary review of the submission. At this stage, the editors are scanning for relevancy to JMCP's readership and a suitable level of quality of research and writing. Articles that pass this review are then sent to peer reviewers.

JMCP maintains a large database of volunteer peer reviewers who are experts in their respective fields and volunteer time to carefully review submitted manuscripts for suitability to publish. Each reviewer self-selects areas of expertise to facilitate matching of articles and reviewers. When an editor uses the database to send out a paper for peer review, the editor typically invites 6 to 8 potential peer reviewers with matching areas of expertise. Potential reviewers are contacted via email and asked to accept or decline. Once the target number of 3 reviewers have accepted, no additional reviewers can accept the invitation. Sometimes it is difficult to identify even 3 reviewers, particularly for obscure subjects or during busy times of the year.

\section{TABLE 1 Five Practices of Reputable Journals}

\begin{tabular}{|c|c|}
\hline Practice & Description \\
\hline $\begin{array}{l}\text { 1. Reputable journals } \\
\text { have a peer-review } \\
\text { process. }\end{array}$ & $\begin{array}{l}\text { - Thorough review and critique of article provided } \\
\text { by experts in the field } \\
\text { - Used to determine whether or not journal will } \\
\text { publish article }\end{array}$ \\
\hline $\begin{array}{l}\text { 2. Reputable journals } \\
\text { have an editorial } \\
\text { board. }\end{array}$ & $\begin{array}{l}\text { - Board of experts in relevant field that serve in } \\
\text { advisory capacity } \\
\text { - Subject matter expertise and geography of board } \\
\text { members should match scope of journal }\end{array}$ \\
\hline $\begin{array}{l}\text { 3. Reputable journals } \\
\text { follow recognized } \\
\text { publishing standards. }\end{array}$ & $\begin{array}{l}\text { - Recognized standards for publishing practices } \\
\text { used by journals to guide operations } \\
\text { - Examples include ICJME and COPE }\end{array}$ \\
\hline $\begin{array}{l}\text { 4. Reputable journals } \\
\text { are transparent about } \\
\text { levied fees. }\end{array}$ & $\begin{array}{l}\text { - Processing or publication fee is to generate } \\
\text { revenue to cover journal expenses } \\
\text { - Transparency reduces real or perceived influence } \\
\text { of fees on publication decisions }\end{array}$ \\
\hline $\begin{array}{l}\text { 5. Reputable journals } \\
\text { are indexed. }\end{array}$ & $\begin{array}{l}\text { - Databases of journals meeting quality selection } \\
\text { criteria to be indexed } \\
\text { - Examples include MEDLINE and Web of Science }\end{array}$ \\
\hline
\end{tabular}

COPE $=$ Core Practices by the Committee on Publication Ethics;

ICJME = Recommendations for the Conduct, Reporting, Editing and Publication of Scholarly Work.

Peer reviewers are asked to complete their reviews within 2 weeks. Often, reviewers ask for an extension. Because reviewers are volunteers, the journal staff works to balance the allotted review time with author expectations for an expeditious review. Peer reviewers provide 2 items to the editor: (1) a Word version of the article with comments and edits using track changes and (2) a scoring sheet. The scoring sheet quantifies the domains of relevancy, originality, quality, bias, and clarity of writing. The scoring sheet also includes a publication recommendation (publish, revise and resubmit, or do not publish). JMCP uses a single-blind process, where the identities of the authors are revealed to the peer reviewers, but the identities of the peer reviewers are blinded to the authors.

In an effort to ensure quality reviews, the peer reviewers themselves are also subjected to peer review by the journal editors. When editors review the scoring sheets and comments submitted by peer reviewers, they use the information to rate the output of each peer reviewer (e.g., poor, fair, good, very good, exceptional). This rating is included in the peer-reviewer database. Over time, reviewers with low-quality reviews will not be invited by editors to review future articles.

Although the details of the peer-review process may vary by journal, authors should expect a thorough peer review when they submit a paper. A review returned to the author with few or no comments should be considered suspect, since every paper has room for improvement when reviewed by experts in the field. Further, a review that is promised in a matter of days should be considered suspect. The rigorous peer-review 
process just described is time consuming. Authors should expect that journals and reviewers dedicate a reasonable amount of time to reviewing their work.

\section{Reputable journals have an editorial board.}

As with most organizations, reputable journals assemble a board of experts in relevant areas to serve in an advisory capacity. For newer journals, board members are often responsible for conducting peer reviews and submitting papers. Board members for mature journals generally focus more on defining journal policies and promoting the journal within their spheres of influence. Additional responsibilities may include solicitation of authors and peer reviewers, identification of topics for themed issues, and advising the editors. Board members are typically volunteers selected by the editor. Editors aim to construct a board that matches the scope of the journal in terms of subject matter expertise and geography. Boards should also be diverse in expertise, experience, and demographics. Although women are underrepresented across pharmacy journal editorial boards, the gender gap is narrowing. ${ }^{11}$

JMCP maintains an editorial advisory board composed of experts in managed care pharmacy. The primary function of the board is to ensure that JMCP is of the highest quality, is practice changing, and improves patient health care outcomes through scientific content relevant to managed care pharmacy. The board maintains 20-25 volunteer members who are solicited through an open call for volunteers each fall. To be selected, an applicant must have a history of serving as a highquality peer reviewer for JMCP and be an experienced editor, reviewer, or author. Further, our editorial advisory board composition reflects the scope of our journal, with representation from academia, pharmacy benefit managers, health plans, pharmaceutical companies, integrated delivery networks, and consultancies.

In contrast, many predatory journals have editorial boards, but they may consist of members who lack expertise pertaining to the scope of the journal, are unknown to experts in the field, or reside outside of the country in which the journal is published (although this alone can be a poor predictor given the international scope of many journals). Predatory journals are known for aggressively soliciting editorial board members and have been reported to "appoint" authors to their board without the person's knowledge.

The extent of deception is depicted by a well-known "sting" operation carried out by a team of psychologists across Europe. ${ }^{12}$ The team created a fictitious scientist named Dr. Anna O. Szust (Oszust is Polish for "fraud") and applied on her behalf to the editorial boards of 360 journals, using a fictitious curriculum vitae with fake journals and book titles. Forty predatory journals (as classified by Dr. Beall) appointed her as editor, some within mere hours of being contacted. In contrast, no journals indexed by the Web of Science, an indicator of journal quality (see \#5 below for a discussion of indexing), appointed Dr. "Fraud" as editor.

Although the extent of these devious practices by journals can trick even the savviest of authors, users should search a journal's website for information on its editorial advisory board and its members when evaluating a journal.

\section{Reputable journals follow recognized publishing standards.}

Just as there are clinical guidelines for the practice of medicine, there are publication guidelines for use by academic journals. These guidelines recommend best practices for topics including authorship designation, journal management, and handling allegations of misconduct. The 2 most widely used U.S. journal guidelines are the Recommendations for the Conduct, Reporting, Editing and Publication of Scholarly Work by the International Committee of Medical Journal Editors (ICJME) and the Core Practices by the Committee on Publication Ethics (COPE) ${ }^{13,14}$ both of which are followed by JMCP. Reputable journals will use these, or similar sources, to guide their practices.

Some predatory journals may claim to follow these guidelines but instead intentionally misrepresent their own practices. It may be impossible for an author to identify a journal that intentionally misrepresents its publishing practices at face value. Therefore, authors should become familiar with these guidelines and formulate expectations for working with reputable journals. Then, authors will be more likely to spot unscrupulous practices when they occur.

\section{Reputable journals are transparent about levied fees.}

Peer-reviewed journals require business models to operate. Expenses can include publishers or publishing staff, website, electronic submission system, printing, and shipping costs. Although more articles are being published electronically, nonprint costs still must be covered. Many journals cover expenses by requiring readers to subscribe to the journal or pay a fee to read an article. However, a push to make science more accessible has led to more journals becoming open access, meaning publications are available at no cost to the reader. JMCP has always been an open access journal. The publisher, AMCP, and the editorial team continue to stand behind the principle that access to published scientific research should be free and open.

However, as journals move to an open access model, charging authors a processing or publication fee is one way to generate revenue to cover journal expenses. This is sometimes called "pay to publish." Other factors contributing to this practice include declining pharmaceutical advertising in print journals and the switch to web-based publishing.

Processing fees can be tricky business for journals. There is an inherent conflict of interest in this model because the journal may be financially incentivized to accept papers, since accepted papers result in revenue. Journals that rely almost 
exclusively on publication fees tend to be less discerning in the articles they publish and generally less reputable. An author should not assume that any journal that requires a fee is predatory, since many reputable journals do so today. However, authors should expect the journal to be transparent about its fees. For example, a journal should not levy a surprise required fee that is only disclosed after an article has been accepted.

$J M C P$ is open access, and we do not require a processing fee for our authors. However, many of our authors are interested in a quicker route to publication. To meet this need, we have an optional expedited publication-for a fee-which shortens the time from final acceptance to publication from approximately 4 months down to 5 weeks. We call this our Express E-publication option. To avoid any real or perceived influence on the publication decision, we only offer this option to our authors after the article has been accepted. In this way, there is no financial incentive for the editors to accept a given article. The fee covers expedited publication costs and contributes to the overall operating budget of the journal. Although many of our authors choose this option because they are highly interested in a rapid publication, the traditional route to print with no fee is always available to all authors.

\section{Reputable journals are indexed.}

Practitioners and researchers use databases such as MEDLINE and Web of Science to search the peer-reviewed literature. Journals indexed in these databases have passed a selection process to be included, so users can generally trust them to be reputable. To be indexed in MEDLINE, part of the National Library of Medicine PubMed system, a journal must meet extensive evaluation criteria related to quality of content, quality of editorial work, and production quality. ${ }^{15}$ Journals are only reviewed for inclusion in MEDLINE 3 times per year, so new journals may not yet be indexed. Similarly, to be included in Web of Science, a team of editors reviews each journal against 28 criteria evaluating editorial rigor and best practices. ${ }^{16} \mathrm{JMCP}$ is indexed in MEDLINE and the Web of Science.

In short, practitioners and researchers can continue to use these databases and be confident that their searches will not yield articles published in predatory journals. Users should remember, however, that a journal that is not indexed should not automatically be assumed to be predatory; it may simply be too new to be listed.

\section{Conclusions}

Given the growth of and aggressive tactics used by predatory journals, authors and readers must learn how to distinguish these publications from trusted, reputable journals. The criteria described herein, the publishing practices of JMCP, and other published resources, ${ }^{3,7-10}$ can aid users in this discernment. Managed care authors and researchers should consider these criteria when determining where to publish their papers and whether or not to serve as an editorial board member or peer reviewer when requested. Managed care and other health care policymakers should consider these criteria when identifying studies for consideration in their decision making.

Although peer-reviewed publishing must evolve to keep pace with the rapid growth of data and analytics in medicine, the field can never compromise on ethical and rigorous publishing practices. Predatory journals pose a threat to the very bedrock of the scientific process. It is incumbent upon all members of the scholarly institution-authors, reviewers, and readers-to protect peer-reviewed publishing by avoiding engagement in any activities with predatory journals. The public's health depends on it.

\section{Author}

LAURA E. HAPPE, PharmD, MPH, Associate Professor, University of Florida, Gainesville, and Editor-in-chief, Journal of Managed Care E Specialty Pharmacy, Alexandria, Virginia.

AUTHOR CORRESPONDENCE: Laura E. Happe, PharmD, MPH, JMCP, 675 N. Washington St., Alexandria, VA 22314.

Tel.: 727.488.2700; Email: lhappe@jmcp.org.

\section{DISCLOSURES}

No funding was received for the writing of this article. The author is editorin-chief of the Journal of Managed Care \& Specialty Pharmacy and has nothing to disclose.

\section{REFERENCES}

1. American Medical Writers Association, European Medical Writers Association \& International Society for Medical Publication Professionals AMWA-EMWA-ISMPP joint position statement on predatory publishing Curr Med Res Opin. 2019;35(9):1657-58.

2. Beall J. "Predatory" open-access scholarly publishers. Charleston Advis. 2010;11:10-17. Available at: https://core.ac.uk/reader/11886760. Accessed June 25, 2020.

3. Beall's list of predatory journals and publishers. January 15, 2017. Available at: https://beallslist.net/standalone-journals/. Accessed June 25, 2020.

4. Straumsheim C. No more 'Beall's List.' Inside Higher Ed. January 18, 2017. Available at: https://www.insidehighered.com/news/2017/01/18/librarianslist-predatory-journals-reportedly-removed-due-threats-and-politics. Accessed June 25, 2020.

5. Pyne D. The rewards of predatory publications at a small business school. Journal of Scholarly Publishing. 2017:48(3):137-60. Available at: https:// utpjournals.press/doi/10.3138/jsp.48.3.137. Accessed June 25, 2020.

6. Shen C, Björk B. 'Predatory' open access: a longitudinal study of article volumes and market characteristics. BMC Med. 2015;13:230. Available at: https://doi.org/10.1186/s12916-015-0469-2. Accessed June 25, 2020.

7. Baker EF, Iserson KV, Aswegan AL, et al. Open access medical journals: promise, perils and pitfalls. Acad Med. 2019;94(5):634-39. 
8. Eriksson S, Helgesson G. The false academy: predatory publishing in science and bioethics. Med Health Care and Philos. 2017;20(2):163-70.

9. Rele S, Kennedy M, Blas N. Journal evaluation tool. 2017. LMU Librarian Publications \& Presentations. 40. Available at: https://digitalcommons.lmu. edu/librarian_pubs/40. Accessed June 25, 2020.

10. Shamseer L, Moher D, Maduekwe O, et al. Potential predatory and legitimate biomedical journals: can you tell the difference? A cross-sectional comparison. BMC Med. 2017;15(1):28. Available at: https://doi.org/10.1186/ s12916-017-0785-9. Accessed June 25, 2020.

11. Sarna KV, Griffin T, Tarlov E, Gerber BS, Gabay MP, Suda KJ. Trends in gender composition on editorial boards in leading medicine, nursing and pharmacy journals. J Am Pharm Assoc. January 2, 2020. [Epub ahead of print]. Available at: https://www.japha.org/article/S1544-3191(19)30609-0/ fulltext. Accessed June 25, 2020.
12. Sorokowski P, Kulcycki E, Sorokowska A, Pisanski K. Predatory journals recruit fake editor. Nature. 2017;543(7646):481-83.

13. International Committee of Medical Journal Editors. Recommendations for the conduct, reporting, editing, and publication of scholarly work in medical journals. December 2019. Available at: http://www.icmje.org/icmjerecommendations.pdf. Accessed June 25, 2020.

14. Committee on Publication Ethics. Core practices. Available at: https:// publicationethics.org/core-practices. Accessed June 25, 2020.

15. National Library of Medicine. Fact sheet. MEDLINE® journal selection. Available at: https://www.nlm.nih.gov/lstrc/jsel.html. Accessed June 25, 2020.

16. Web of Science Group. Web of Science journal evaluation process and selection criteria. Available at: https://clarivate.com/webofsciencegroup/ journal-evaluation-process-and-selection-criteria/. Accessed June 25, 2020. 